\title{
Influence of Maternal Nutritional Factors on Ovarian Folliculogenesis in Cattle
}

\author{
Do $\mathrm{VH}^{1,2}$ and Taylor-Robinson $\mathrm{AW}^{* 1}$
}

${ }^{1}$ School of Medical \& Applied Sciences, Central Queensland University, Rockhampton, QLD, Australia

${ }^{2}$ National Key Laboratory of Animal Cell Technology, National Institute of Animal Sciences, Hanoi, Vietnam

*Corresponding author: Taylor-Robinson AW, School of Medical \& Applied Sciences, Central Queensland University, Bruce Highway, Rockhampton, QLD 4702, Australia, Tel: 61749232008, E-mail: a.taylorrobinson@cqu.edu.au

Citation: Do VH, Taylor-Robinson AW (2015) Influence of Maternal Nutritional Factors on Ovarian Folliculogenesis in Cattle. J Vet Sci Anim Husb 3(3): 301. doi: 10.15744/2348-9790.3.301

Received Date: May 11, 2015 Accepted Date: June 16, 2015 Published Date: June 18, 2015

\begin{abstract}
Assisted reproductive technologies, such as artificial insemination and embryo transfer, have produced significant outcomes in cattle. These technologies are useful not only for improving fertility but also for increasing the rate of genetic change in beef and dairy livestock. Today, embryo transfer in cattle is both practical and commercially viable. However, bovine embryo transplantation still remains suboptimal under on-farm conditions, one of the main reasons for which may be inefficient nutritional management. The role of nutrition in modulating reproduction and particularly in ovarian function remains unclear. Considerable effort has been made to elucidate the nutritional factors regulating the development of follicles in either a direct or an indirect manner. Moreover, evidence indicates that bovine folliculogenesis is modulated by gonadotropins as well as by metabolic hormones, including growth hormone, leptin, insulin and insulin-like growth factor-1. In addition, metabolites - such as glucose, urea and non-esterified fatty acids - are considered to play a role in regulating ovarian follicular development. Nutrition affects folliculogenesis indirectly by altering the activity of reproductive hormones. Furthermore, nutrition has local impact on the development of follicles at the ovarian level. As a result, nutrition is possibly decisive to the fate of bovine oocyte development, since oocyte quality influences reproductive outcomes such as fertilization and pregnancy rates. Although numerous reviews in the published literature describe nutritional roles in reproduction, the primary focus of this paper is the effect of nutritional factors on folliculogenesis in cattle. A greater understanding of this influence may facilitate nutritional manipulation in order to enhance fertility in cattle in a cost-effective yet very efficient way.
\end{abstract}

Keywords: Nutrition; Folliculogenesis; Ovary; Fertility; Bovine; Cattle; Hormone; Gonadotropin; Leptin; Insulin; IGF-1

\section{Introduction}

The majority of cattle across the world are reared through pastured-base systems, so the availability and quality of grass affects livestock performances, including growth, reproduction and yields of beef and milk. Nutrition provides a basic foundation for reproductive performance; therefore, it is apparent that nutrition plays an important role in enhancing fertility in cattle [1]. However, the effect of nutritional strategies on reproduction is open to debate. Fertility can be improved through nutritional management [2]; nonetheless, the study of Mousavi et al. [3] on the effect of fish meal or n-3 fatty acids on ovarian and uterine dynamics, indicates no effect of such diets on ovarian function. Consistent with this, Velazquez et al. [4] reported that nutritional strategies do not increase the efficiency of bovine superovulation. Robinson et al. [5], however, contended that high-plane feed does enhance oocyte and embryo quality. Moreover, undernutrition has a negative impact on fertility [6,7], suggesting that an adequate supply of nutrients is very important for normal reproduction performance in livestock. A good example is dairy cattle during the transition period, when postpartum cows may suffer from a negative energy balance (NEB). This results particularly in deleterious effects on reproduction in normally high-yielding animals since all nutrients are required prior to milk production. Although the roles of nutrition in reproduction are often complicated and experimental results have been inconsistent [8], numerous studies have attempted to elucidate the functions of metabolites and metabolic hormones in regulation of folliculogenesis. For instance, Silva et al. [9] demonstrated clearly the role of growth hormone (GH) and insulin-like growth factor-1 (IGF-1) systems in controlling ovarian folliculogenesis. Furthermore, the influence of nutrition is either direct or indirect [6]. Published research covers primarily the role of gonadotropin hormones $(\mathrm{GnRH})$ in regulating the development of follicles; here, we describe the interrelationship between nutrition and follicular development in cattle. An appreciation of this complex relationship would facilitate enhanced manipulation of reproduction though improved nutritional strategies.

\section{Ovarian folliculogenesis in cattle}

Folliculogenesis is defined as "an intricate process that involves the proliferation and differentiation of both somatic and germ cells" [10]. It is regulated by GnRH, metabolic hormones and local factors like IGF-1 systems. Primordial follicles form initially 
during the foetal life of a mammal [10]; however, it is important to note that early folliculogenesis and the start of primordial follicle growth are not influenced by GnRH [11]. Monniaux et al. [12] maintain that anti-Müllerian hormone (AMH), derived from the granulosa cells of developing follicles, reflects the ovarian follicular reservoir. For example, Gamarra et al. [13] reported significantly more small follicles (ranging from $2-7 \mathrm{~mm}$ in diameter) in heifers with medium and high plasma AMH than in those with low plasma AMH. Each primordial follicle passes through a continuous series of progressively more developed stages (primary, secondary, pre-antral and antral) towards either ovulation or, in most cases, atresia - the process by which immature ovarian follicles degenerate and are subsequently re-absorbed.

Jaiswal et al. [14] contend that a two-wave pattern or three-wave pattern of follicular development is predictable and repeatable within a single oestrous cycle in cattle. During a follicle wave, each cohort of follicles passes through three stages: growing; static; and regressing. In the growing phase, recruitment of follicles is controlled by follicle-stimulating hormone (FSH) [15]. In this stage, the growth rates of recruited follicles around 4 days are similar [14], and the difference occurs during the following static stage when growing follicles progress through deviation. It is well established that the first follicle requiring luteinizing hormone (LH) receptors becomes the dominant follicle while the others depending on FSH regress in response to decreasing concentrations of circulating FSH [11]. Ginther et al. [16] showed that the difference in growth rates between the largest subordinate follicle and the future dominant follicle is accounted for by the time taken for deviation or early static stage. They found that the decisive stage occurs at approximately $8 \mathrm{~mm}$ and that the dominant follicle produces inhibin hormone which suppresses development of subordinate follicles, resulting in their apoptosis. Moreover, a developing dominant follicle secretes oestrogen that is involved in initiation of luteolysis at the end of the luteal phase. Consequently, the frequency of LH pulses leads to the ovulation of a selected dominant follicle. It is apparent that GnRH play a key role in modulation of folliculogenesis [17,18]; however, follicular growth is monitored by sophisticated interactions between extra-ovarian factors, such as gonadotropins and metabolic factors, and intraovarian factors [18] that are described later.

\section{Indirect effects of nutrition on ovarian folliculogenesis}

It is evident that metabolic hormones interact with GnRH to regulate ovarian follicular development. Diskin et al. [6] pointed out that nutrition indirectly controls folliculogenesis by altering levels of GnRH. It has been shown that a range of metabolic hormones, such as leptin, insulin and IGF-1, may also mediate reproduction. Leptin is a peptide secreted by adipose tissues [19,20], which performs crucial roles in control of feed intake and body weight [20]. In addition, leptin is considered a mediator that is responsive to nutritional stress [21].

In a study of goats, Batista et al. [19] demonstrated that leptin and its receptor expressed at mRNA and protein levels are present in all constituents of antral follicles, with particularly high levels in granulosa cells. Williams et al. [22] revealed that leptin can stimulate GnRH secretion in cattle. However, Amstalden et al. [7], using in vitro approaches, suggested that in fully fed cattle leptin does not stimulate release of GnRH from the hypothalamus or adenohypophyseal explants and cells. They further noted that in well-fed animals the effect of leptin on the release of GnRH is limited. In corroboration, Zieba et al. [21] claimed that leptin does not increase the frequency of LH pulses in peripubertal heifers regardless of nutritional status and that in fully fed cattle leptin has no impact on the secretion of GnRH and LH. Also, supplementation of leptin in in vitro maturation medium does not confer beneficial effects on the developmental competence of prepubertal bovine oocytes [23]. Nevertheless, Block et al. [24] demonstrated that leptin is regulated by insulin and GH, and that undernutrition leads to reduction of insulin plasma concentration.

Similarly to leptin, insulin acts as an indirect regulator of development of follicles. In the case of high-producing dairy cows, Garnsworthy et al. [25] reported that both rumen-digestible starch and rumen-bypass starch are effective at maintaining plasma insulin and ovarian function. Lucy et al. [26] noted that in dairy cows nutrition partitioning causes liver failure in response to GH and to a low production of IGF-1. Interestingly, IGF-1 in association with GH and insulin also plays an indirect role in folliculogenesis in cattle. Chase et al. [27], working with Brahman cattle, showed that administration of GH or GH plus insulin elevates significantly circulatory concentrations of IGF-1. However, it appears that IGF-1 has a local influence in follicular development, and this is discussed in detail below. In summary, orchestrated by gonadotropins, metabolic hormones regulate bovine folliculogenesis. It is in this context that the question can be posed of whether nutritional factors can directly modulate folliculogenesis.

\section{Direct effects of nutrition on ovarian folliculogenesis}

Nutrients are indispensable for cell maintenance, growth and reproduction. Metabolic hormones exert a direct influence on folliculogenesis at the ovarian level. In intensive-based feeding systems, the addition of either rumen-digestible starch or, less so, bypass starch affects the number and size of follicles [25]. Diskin et al. [6] contended that nutrition directly regulates ovarian development via the hepatic system. In agreement with this proposal, Dawuda et al. [28] noted that feed intake may affect the hepatic clearance rate of steroid hormones and that consequently circulatory levels of these hormones may influence folliculogenesis.

Metabolic hormones such as leptin, insulin and IGF-1 either suppress or stimulate developing follicles in a concentration-dependent manner. Chagas et al. [8] highlighted the local effect of IGF-1 on follicles. Shahiduzzaman et al. [29] experimented with inoculation of IGF-1 into dominant follicles. Interestingly, they found that treatment of the second follicle led to an inhibitory effect on the development of the largest follicle by decreasing its growth rate, and thereby measured diameter, suggesting that IGF-1 enhances 
development of the follicle during the deviation period. This may explain why reductions in insulin and IGF-1 delay the oestrus cycle and impair the quality of oocytes and corpus luteum function. This is consistent with the report of Cavestany et al. [30] showing that the size of the dominant follicle is correlated with IGF-1 concentrations in peripheral blood, and that IGF-1 stimulates development of a larger dominant follicle. Furthermore, Spicer et al. [31] revealed that IGF-1 stimulates bovine granulosa cell proliferation. In postpartum cattle, severe NEB decreases hepatic expression of insulin-like growth factor binding proteins (IGFBP)-3, -4, -5 and -6, but increases levels of IGFBP-2 [32]. Synthetic IGF-1 is depressed by severe NEB [32]. A dynamic activity of the IGF system is necessary for follicular selection and advancement before the preovulatory stage [33].

Consistent with the action of IGF-1, insulin plays a role in regulation of ovarian function. Robinson et al. [5] showed that resumption of ovarian activity in postpartum cattle is stimulated mainly by insulin. Castañeda-Gutiérrez et al. [34] noted that in dairy cows glucose is depressed and insulin levels decrease sharply during the transition period. Moreover, Garnsworthy et al. [35] reported that raised plasma insulin concentrations are capable of restoring ovarian activity; nonetheless, they concluded that alteration of levels of this metabolic hormone by introduction of metabolisable protein such as leucine does not have a significant effect on ovarian function in lactating dairy cows. Starch supplements may also not affect plasma insulin concentration and ovarian function since both the products of rumen-digestible starch, propionate, which is absorbed across the rumen wall, and glucose from bypass starch absorbed from the small intestine, affect levels of plasma insulin [25].

It is important to note that metabolites are also involved in regulation of ovarian function. Oliveira Filho et al. [2] showed that blood cholesterol, triglycerols and total lipid pattern each correlate with the development of follicles. These authors further suggested that nutritional supplementation before the parturition period is beneficial to maintaining body condition score (BCS) since this strategy efficiently increases availability of cholesterol for assuring ovarian function as well as for improving resumption of ovarian activity. In cattle, BCS is a criterion that is used to determine the nutritional status of an animal. Postpartum cattle in particular experience a NEB due to mobilisation of body reserves for maintenance and lactation [6,13]. A deep NEB reduces the LH pulse, which thereby influences dominant follicles [36]. As a consequence of a NEB there is an increase in plasma non-esterified fatty acids (NEFA). Burke and Roche [37] found that plasma concentrations of NEFA are accelerated when cows have low pasture intakes. However, Burke et al. [38] claimed that the increase in nonstructural carbohydrate content of the transition diet did not affect postpartum anovulatory intervals in grazing cattle.

In accordance with the influence of glucose and lipid, protein may also play a role in follicular development. Cattle that are fed regularly with high levels of dietary urea are thought to tolerate the toxicity of urea due either to rumenal microflora increasing methane production through their ammonia digestion or to a change in the cows' hepatic metabolism [39]. Dawuda et al. [40], who investigated the effect of excess intake of rapidly degradable nitrogen on metabolism and reproduction in lactating cows, reported that addition of $250 \mathrm{~g}$ urea per cow per day neither significantly increases milk yield nor elevates plasma concentrations of insulin and IGF-1. In agreement with this study, Moallem et al. [41] concluded that although supplementation of high dietary crude protein for non-lactating heifers results in penetration of urea into pre-ovulatory follicles, this does not impair the features of such follicles.

In extensive farming systems, in spring an imbalance in protein digestion may have a potentially profound impact on the quality of bovine oocytes. However, excess protein supplementation would appear to cause a detrimental impact on the developmental competence of oocytes. Velazquez [4] noted that urea impairs the maturity of oocytes and decreases their quality. This is characterised by a gradual decrease in dry matter intake by cattle and their mobilisation of body fat reserves, resulting in an increase in NEFA but with frequently observed insulin reduction [34].

\section{Nutritional strategies to improve reproductive performance in cattle}

Further to consideration of the direct and indirect effects of metabolites and nutrients on fertility in cattle, it is clear that nutritional strategies should be sought to improve follicular quantity and quality. Childs et al. [42] showed that supplements of dietary n-3 polyunsaturated fatty acids increase IGF-1 concentrations, leading to improvement in fertility. Incorporation of short-term nutritional supplementation into artificial reproductive technologies such as artificial insemination and embryo transfer may improve outcomes. Gamarra et al. [13] reported that for dairy heifers addition of short-term dietary propylene glycol results in a series of changes in metabolites, metabolic hormones, plasma progesterone and small follicle population, causing stimulation of follicular growth. In pasture-based systems, it is beneficial to supplement a highly nutritious diet for multiparous cows in the prepartum period as this strategy enhances ovarian resumption and stimulates the onset of ovulation after calving [25]. Increased provision of dietary starch leads to a rise in plasma insulin, producing a change in oocyte quality. Under pastoral conditions of low quality grass, and availability of a cereal-based supplement equivalent to a $0.9 \%$ of live weight concentration is crucial to supply energy, which promotes elevated insulin concentrations in blood [36]. Administration of both GH and insulin significantly improves plasma IGF-1, IGFBP-3, -4 and -5, but decreases IGFBP-2 and urea-nitrogen [27].

In contrast, it appears that in cattle with a high nutritional status, represented by a high BCS, the effects of nutritional supplementation on reproductive performance remain unclear. Santos et al. [43] noted that in moderately underfed non-lactating cows nutritional supplementation can enhance the quality of oocytes and embryos. Nevertheless, considerable research on nutritional additions for well-fed cattle has shown that such approaches may not be effective to enhance superovulatory yields [4]. 


\section{Conclusion}

It is evident that nutrition affects bovine ovarian function. In addition, the effects of nutrients as well as of metabolic hormones on folliculogenesis occur both by direct and indirect means. Hence, the diet of cattle probably changes the progress of follicular development, resulting in fluctuations in the turnover of follicles. The mechanism of ovarian regulation of metabolic hormones remains unclear, suggesting that further investigations are required to elucidate this underlying metabolic pathway. Dietary improvements to pasture and forage plants should be considered since they are a very cost-effective way to enhance animal reproductive performance.

\section{Acknowledgement}

Financial support for our work is provided by CQUniversity and Australian Reproductive Technologies.

\section{References}

1.Gong JG (2002) Influence of metabolic hormones and nutrition on ovarian follicle development in cattle: practical implications. Domest Anim Endocrinol 23: $229-41$.

2. Oliveira Filho BD, Toniollo GH, Oliveira AF, Viu MA, Ferraz HT, et al. (2010) The effect of offering an energy and protein supplement to grazing canchim beef cows either postpartum or both pre- and postpartum on lipid blood metabolites and folliculogenesis. Anim Reprod Sci 121: 39-45.

3.Moussavi AR, Gilbert RO, Overton TR, Bauman DE, Butler WR, et al. (2007) Effects of feeding fish meal and n-3 fatty acids on ovarian and uterine responses in early lactating dairy cows. J Dairy Sci 90: 145-54.

4. Velazquez MA (2011) The role of nutritional supplementation on the outcome of superovulation in cattle. Anim Reprod Sci 126: 1-10.

5. Robinson JJ, Ashworth CJ, Rooke JA, Mitchell LM, McEvoy TG (2006) Nutrition and fertility in ruminant livestock. Anim Feed Sci Tech 126: 259-76.

6. Diskin MG, Mackey DR, Roche JF, Sreenan JM (2003) Effects of nutrition and metabolic status on circulating hormones and ovarian follicle development in cattle. Anim Reprod Sci 78: 345-70.

7. Amstalden M, Harms PG, Welsh TH, Randel RD, William GL (2005) Effects of leptin on gonadotropin-releasing hormone release from hypothalamicinfundibular explants and gonadotropin release from adenohypophyseal primary cell cultures: further evidence that fully nourished cattle are resistant to leptin. Anim Reprod Sci 85: 41-52.

8. Chagas LM, Bass JJ, Blache D, Burke CR, Kay JK, et al. (2007) New perspectives on the roles of nutrition and metabolic priorities in the subfertility of highproducing dairy cows. J Dairy Sci 90: 4022-32.

9. Silva JR, Figueiredo JR, van den Hurk R (2009) Involvement of growth hormone (GH) and insulin-like growth factor (IGF) system in ovarian folliculogenesis. Theriogenology 71: 1193-208.

10. Hernandez-Medrano JH, Campbell BK, Webb R (2012) Nutritional influences on folliculogenesis. Reprod Domest Anim 47: 274-82.

11. Webb R, Garnsworthy PC, Gong JG, Armstrong DG (2004) Control of follicular growth: local interactions and nutritional influences. J AnimSci 82: E63-74.

12. Monniaux D, Rico C, Larrogue H, Dalbiès-Tran R, Médique C, et al. (2010) Anti-Müllerian hormone, an endocrine predictor of the response to ovarian stimulation in the bovine species. Gynecol Obstet Fertil 38: 465-70.

13. Gamarra G, Ponsart C, Lacaze S, Guienne BL, Deloche MC, et al. (2014) Short term dietary propylene glycol supplementation affects circulating metabolic hormones, progesterone concentrations and follicular growth in dairy heifers. Livestock Sci 162: 240-51.

14. Jaiswal RS, Singh J, Marshall L, Adams GP (2009) Repeatability of 2-wave and 3-wave patterns of ovarian follicular development during the bovine estrous cycle. Theriogenology 72: 81-90.

15. Fortune JE (1993) Follicular dynamics during the bovine estrous cycle: a limiting factor in improvement of fertility? Anim Reprod Sci 33: 111-25.

16. Ginther OJ, Kot K, Kulick LJ, Wiltbank MC (1997) Emergence and deviation of follicles during the development of follicular waves in cattle. Theriogenology 48: 75-87.

17. Forde N, Beltman ME, Lonergan P, Diskin M, Roche JF, et al. (2011) Oestrous cycles in Bos taurus cattle. Anim Reprod Sci 124: 163-9.

18. Webb R, Garnsworthy PC, Campbell BK, Hunter MG (2007) Intra-ovarian regulation of follicular development and oocyte competence in farm animals. Theriogenology 68: S22-9.

19. Batista AM, Silva DM, Rego MJ, Silva FL, Silva EC, et al. (2013) The expression and localization of leptin and its receptor in goat ovarian follicles. Anim Reprod Sci 141: 142-7.

20. Boland MP, Lonergan P, O'Callaghan D (2001) Effect of nutrition on endocrine parameters, ovarian physiology, and oocyte and embryo development. Theriogenology 55: 1323-40.

21. Zieba DA, Amstalden M, Williams GL (2005) Regulatory roles of leptin in reproduction and metabolism: a comparative review. Domest Anim Endocrinol 29: 166-85.

22. Williams GL, Amstalden M, Garcia MR, Stanko RL, Nizielski SE, et al. (2002) Leptin and its role in the central regulation of reproduction in cattle. Domest Anim Endocrinol 23: 339-49.

23. Córdova B, Morató R, de Frutos C, Bermejo-Álvarez P, Paramio T, et al. (2011) Effect of leptin during in vitro maturation of prepubertal calf oocytes: embryonic development and relative mRNA abundances of genes involved in apoptosis and oocyte competence. Theriogenology 76: 1706-15.

24. Block SS, Rhoads RP, Bauman DE, Ehrhardt RA, McGuire MA, et al. (2003) Demonstration of a role for insulin in the regulation of leptin in lactating dairy cows. J Dairy Sci 86: 3508-15.

25. Garnsworthy PC, Gong JG, Armstrong DG, Mann GE, Sinclair KD, et al. (2009) Effect of site of starch digestion on metabolic hormones and ovarian function in dairy cows. Livestock Sci 125: 161-8.

26. Lucy MC, Verkerk GA, Whyte BE, Macdonald KA, Burton L, et al. (2009) Somatotropic axis components and nutrient partitioning in genetically diverse dairy cows managed under different feed allowances in a pasture system. J Dairy Sci 92: 526-39. 
27. Chase CC Jr, Elsasser TH, Spicer LG, Ridley DG, Lucy MC, et al. (2011) Effect of growth hormone administration to mature miniature Brahman cattle treated with or without insulin on circulating concentrations of insulin-like growth factor-I and other metabolic hormones and metabolites. Domest Anim Endocrinol 41: $1-13$.

28. Dawuda PM, Scaife JR, Hutchison JS, Sinclair KD (2002) Mechanisms linking under-nutrition and ovarian function in beef heifers. Anim Reprod Sci 74: 11-26.

29. Shahiduzzaman AK, Beg MA, Palhao MP, Siddiqui MA, Shamsuddin M, et al. (2010) Stimulation of the largest subordinate follicle by intrafollicular treatment with insulin-like growth factor 1 is associated with inhibition of the dominant follicle in heifers. Theriogenology 74: 194-201.

30. Cavestany D, Vinoles C, Crowe MA, La Manna A, Mendoza A (2009) Effect of prepartum diet on postpartum ovarian activity in Holstein cows in a pasturebased dairy system. Anim Reprod Sci 114: 1-13.

31. Spicer LJ, Bossis I, Wettermann RP (2008) Effect of plasma from cyclic versus nutritionally induced anovulatory beef heifers on proliferation of granulosa cells in vitro. Domest Anim Endocrinol 34: 250-3.

32.Fenwick MA, Fitzpatrick R, Kenny DA, Diskin MG, Patton J, et al. (2008) Interrelationships between negative energy balance (NEB) and IGF regulation in liver of lactating dairy cows. Domest Anim Endocrinol 34: 31-44.

33. Monniaux D (2012) Superovulatory responses and embryo production in ruminants: lessons from ovary. Proceedings of the $28^{\text {th }}$ Annual Meeting A.E.T.E: 7-40.

34. Castañeda-Gutiérrez E, Pelton SH, Gilbert RO, Butler WR (2009) Effect of peripartum dietary energy supplementation of dairy cows on metabolites, liver function and reproductive variables. Anim Reprod Sci 112: 301-15.

35. Garnsworthy PC, Gong JG, Armstrong DG, Newbold JR, Marsden M, et al. (2008) Nutrition, metabolism, and fertility in dairy cows: 3. Amino acids and ovarian function. J Dairy Sci 91: 4190-7.

36. Aguilar-Pérez C, Ku-Vera J, Centurión-Castro F, Garnsworthy PC (2009) Energy balance, milk production and reproduction in grazing crossbred cows in the tropics with and without cereal supplementation. Livestock Science 122: 227-33.

37. Burke CR, Roche JR (2007) Effects of pasture feeding during the periparturient period on postpartum anovulation in grazed dairy cows. J Dairy Sci $90: 4304-12$.

38. Burke CR, Kay JK, Phyn CVC, Meier S, Lee JM, et al. (2010) Effects of dietary nonstructural carbohydrates pre- and postpartum on reproduction of grazing dairy cows. J Dairy Sci 93: 4292-6.

39. Dawuda PM, Scaramuzzi RJ, Leese HJ, Hall CJ, Peters AR, et al. (2002) Effect of timing of urea feeding on the yield and quality of embryos in lactating dairy cows. Theriogenology 58: 1443-55.

40. Dawuda PM, Scaramuzzi RJ, Drew SB, Biggadike HJ, Laven RA, et al. (2004) The effect of a diet containing excess quickly degradable nitrogen (QDN) on reproductive and metabolic hormonal profiles of lactating dairy cows. Anim Reprod Sci 81: 195-208.

41. Moallem U, Blanck R, Lehrer H, Livshitz L, Zachut M, et al. (2011) Effects of high dietary crude protein on the characteristics of preovulatory follicles in dairy heifers. J Dairy Sci 94: 785-92.

42. Childs S, Hennessy AA, Sreenan JM, Wathes DC, Cheng Z, et al. (2008) Effect of level of dietary n-3 polyunsaturated fatty acid supplementation on systemic and tissue fatty acid concentrations and on selected reproductive variables in cattle. Theriogenology 70: 595-611.

43. Santos JE, Cerri RL, Sartori R (2008) Nutritional management of the donor cow. Theriogenology 69: 88-97.

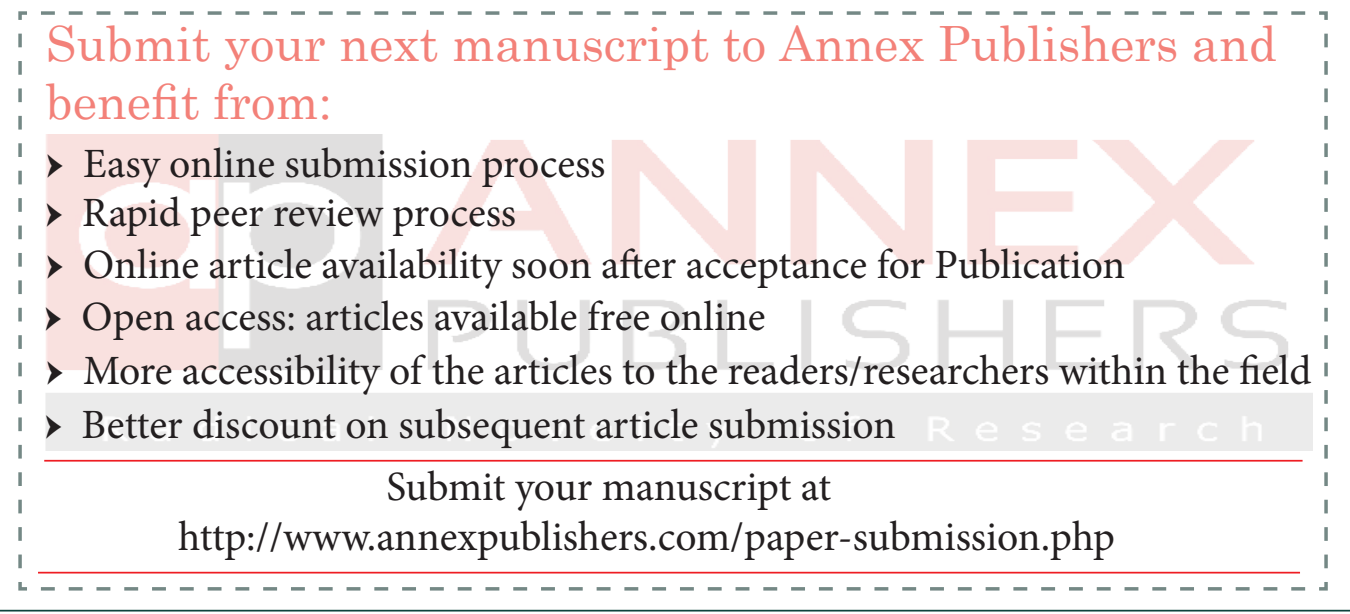

